\title{
Timing of Apple Fruit Infection by Neofabraea perennans and Neofabraea kienholzii in Relation to Bull's-eye Rot Development in Stored Apple Fruit
}

\author{
C. G. Aguilar, Department of Plant Pathology, Washington State University, Pullman 99164; M. Mazzola, United States Department of \\ Agriculture-Agricultural Research Service (USDA-ARS), Tree Fruit Research Laboratory, Wenatchee, WA 98801; and C. L. Xiao, USDA-ARS, \\ San Joaquin Valley Agricultural Sciences Center, Parlier, CA 93648
}

\begin{abstract}
Bull's-eye rot is a postharvest disease of pome fruit in the U.S. Pacific Northwest. The disease is caused by the fungi Neofabraea kienholzii, $N$. malicorticis, $N$. perennans, and $N$. vagabunda. Fruit infection by these pathogens is initiated in the orchard during the fruit-growing season but remains latent at harvest. For fruit held in postharvest cold storage, bull'seye rot symptom development is slow to progress, requiring at least 3 months before symptoms are first visible. In order to determine the timing of preharvest fruit infection in relation to bull's-eye rot development in cold storage, 'Red Delicious' and 'Fuji' apple fruit were inoculated

with a conidial suspension of $N$. perennans or $N$. kienholzii at different inoculation timings throughout the fruit growing seasons of 2012 to 2014. Fruit were harvested and stored at $0^{\circ} \mathrm{C}$ for up to 10 months, during which time disease incidence was recorded periodically. Results from this study demonstrate that apple fruit infection by either pathogen may occur at any point during the growing season. However, infections occurring over the 8-week period immediately prior to harvest yield a higher incidence of bull's-eye rot in stored fruit compared with infections initiated earlier in the growing season.
\end{abstract}

Postharvest fruit rot diseases pose a major limitation to the goal of retaining high-quality, marketable fruit held under prolonged postharvest storage. In the United States, Washington State is the leading producer of apple, amassing a multibillion dollar industry. Such high revenues are attained in part, due to utilization of controlled atmosphere storage which extends the fruit storage period, retaining fruit quality and thus enabling the availability of this important agricultural commodity throughout the year (Thompson 1998). However, postharvest diseases of apple such as blue mold, gray mold, and bull's-eye rot caused by Penicillium spp., Botrytis cinerea, and Neofabraea spp., respectively, can cause reductions to fruit yields as high as 5 to 28\% annually (Spotts et al. 2009; Xiao and Kim 2008). Economic losses resulting from postharvest diseases can be further exacerbated if the pathogen in question presents a quarantine concern for export markets (Xiao et al. 2011). Diseases such as bull's-eye rot caused by Neofabraea spp., Sphaeropsis rot caused by Sphaeropsis pyriputrescens, and speck rot caused by Phacidiopycnis washingtonensis are major production issues for pome fruit growers of the U.S. Pacific Northwest (PNW) (Xiao and Kim 2008; Yigzaw and Bond 2014). In addition to diminishing the appearance and quality of fruit grown for domestic consumption, the pathogens associated with these diseases have potential to jeopardize access to international markets for PNW fruit growers (Warner 2014).

Successful control of postharvest diseases requires an understanding of the host infection process and knowledge of the environmental conditions under which infection may occur. Bull's-eye rot represents a postharvest disease that arises from infection originating in the orchard but remains quiescent or latent at harvest (Bompelx 1978). Managing the disease can be challenging due to the absence of symptoms at harvest and slow progression on fruit destined for cold storage.

In the PNW, Neofabraea kienholzii, N. malicorticis, N. perennans, and $N$. vagabunda are all known to cause bull's-eye rot on fruit of Malus and Pyrus spp., though the distribution of these fungi within this region is geographically fragmented (Kienholz 1938; Spotts et al.

Corresponding author: M. Mazzola; E-mail: Mark.Mazzola@ars.usda.gov

Accepted for publication 24 December 2016.

This article is in the public domain and not copyrightable. It may be freely reprinted with customary crediting of the source. The American Phytopathological Society, 2017.
2009). With the exception of $N$. kienholzii, these fungi are known to overwinter in the orchard either on margins of sunken stem or branch cankers, or as saprophytes on dead wood and leaves (Edney 1956; Tan and Burchill 1972). Information pertaining to the overwintering status of $N$. kienholzii is as of yet unavailable due to its recent discovery and identification as a separate bull's-eye rot-causing species (de Jong et al. 2001; Spotts et al. 2009). Additional hosts of these cankerinducing pathogens include native PNW crabapple (Malus fusca), quince (Cydonia oblonga), serviceberry (Amelanchier spp.), mountain ash (Sorbus acuparia), and hawthorn (Crataegus spp.) (Kienholz 1939; Creemers 2014). These alternative hosts may serve as important sources of inoculum when growing adjacent to apple or pear orchards. Because native crabapple are believed to be the original host of apple anthracnose causal fungi (Kienholz 1939), exclusion of wild crabapple from established orchards as well as proper eradication of infected plant material from the orchard is important in minimizing inoculum buildup (Childs 1929)

In general, conidia released from acervuli of Neofabraea spp. on cankers or other overwintering sources become rain or irrigationsplash dispersed onto neighboring twigs and developing fruit during the apple growing season (Gariepy et al. 2005; Sharples 1959; Wilkinson 1944). Germinating conidia infect fruit by hyphal penetration of epidermal tissue, preferentially through open lenticels on the apple surface (Wilkinson 1944); however, infections of the stem bowl or calyx region of fruit is also possible (Spotts et al. 2009). Though infection is asymptomatic at harvest, over time, fruit held at cold storage begin to develop tan-colored lesions with alternating concentric, dark-brown rings visible on the fruit skin. During advanced stages of bull's-eye decay, white to cream-colored mycelium producing acervuli with cream-colored spore masses can be visible growing from these target-like lesions.

Current recommendations for managing bull's-eye rot rely primarily on pruning cankers from infected trees or applying pre- or postharvest fungicides to fruit (Creemers 2014; Spotts 2014). It is speculated that Neofabraea spp. causing bull's-eye rot are capable of sporulating from cankers and other overwintering sources throughout the entire apple fruit growing season. Given the presence of appropriate environmental conditions, it is plausible that fruit infection may occur at any time during the fruit maturation process (Grove et al. 1992).To assist in the development of effective fungicide spray schedules which minimize application periods, the current study was conducted to identify the timing under which these fungi infect fruit in the orchard in relation to bull's-eye rot development of fruit kept in cold storage. The 
specific objectives of this study were to (i) determine the timing of apple fruit infection by $N$. perennans and $N$. kienholzii in the orchard, in relation to development of bull's-eye rot during postharvest cold storage, and (ii) compare the relative capacity of $N$. kienholzii and $N$. perennans to incite disease on apple fruit at varying stages of fruit maturity, as indicated by differences in disease incidence resulting from artificial fruit inoculations.

\section{Materials and Methods}

Isolate selection. Fruit inoculations in the orchard were conducted with $N$. perennans isolate CLX5396 and N. kienholzii isolate CLX4426. Isolate CLX5396 was originally isolated from decayed 'Gala' fruit harvested from an orchard located in East Wenatchee, WA, whereas isolate CLX4426 originated from decayed 'Fuji' fruit grown in Tonasket, WA. The isolates were obtained from locations where fruit infection by both species was prevalent. These isolates were previously identified to species using molecular and morphological diagnostic techniques (Dugan et al. 1993; Gariépy et al. 2003; Spotts et al. 2009). Isolate CLX4426 was 1 of 10 isolates utilized to formally describe $N$. kienholzii as a separate species capable of inciting bull's-eye rot (Spotts et al. 2009). Fungal isolates were maintained on potato dextrose agar (PDA; Difco, Becton, Dickinson and Company, Sparks, MD) plugs in $15 \%$ glycerol and stored at $-80^{\circ} \mathrm{C}$ for long-term preservation.

Orchard location and inoculation timing. Fruit inoculations were conducted in the field on Fuji apple trees growing in a 0.49-ha block and 'Red Delicious' apple growing in a 0.6-ha block, both planted in 2007 at the Washington State University Sunrise Research Orchard northwest of Palisades, WA $\left(47^{\circ} 25^{\prime} 08^{\prime \prime} \mathrm{N}, 119^{\circ} 54^{\prime} 52^{\prime \prime} \mathrm{W}\right)$.
Experiments were conducted for three consecutive growing seasons, beginning in 2012. Fruit were inoculated on a monthly basis beginning in May at petal fall and continuing until harvest, roughly at a 5- to 6-week interval (Table 1). Under-tree irrigation, pruning, thinning, and pest control were conducted following regional commercial production standards (Bush et al. 2008). Pest control entailed the application of multiple insecticides and herbicides throughout the growing season. Fungicides were not applied to any trees used over the course of this experiment.

Inoculum preparation. Conidial suspensions of $N$. kienholzii and $N$. perennans were prepared from 3-week-old PDA cultures grown in the dark at $20^{\circ} \mathrm{C}$. Cultures were flooded with $10 \mathrm{ml}$ of sterile distilled water and agitated using a sterile inoculation loop to dislodge conidia into the liquid. The resulting spore suspension was then filtered through two layers of sterile cheesecloth to remove mycelial and agar fragments and collected into a sterile Erlenmeyer flask. A hemocytometer was used to determine spore concentration of the suspension and sterile distilled water was used to adjust the suspension to a concentration of $5 \times 10^{5}$ spores $/ \mathrm{ml}$. This spore concentration was selected based on similar fruit inoculation studies done with postharvest decay pathogens prevalent in the PNW (Kim et al. 2014; Sikdar et al. 2014). The suspension was transferred into a plastic spray bottle and kept in a cooler filled with ice until use in inoculations conducted later the same day. Sterile distilled water applied to fruit using plastic spray bottles was used as the control inoculation treatment.

Inoculation procedure. Fruit inoculations in the orchard were conducted in the evenings approximately $3 \mathrm{~h}$ prior to sunset in order to minimize spore exposure to direct sunlight and extreme heat. Trees were selected and assigned to each treatment following a randomized

Table 1. Dates of apple fruit inoculation and harvest for bull's-eye rot field trials conducted at Washington State University Sunrise Research Orchard, and environmental conditions recorded during each fruit inoculation timing

\begin{tabular}{|c|c|c|c|c|}
\hline \multirow[b]{2}{*}{ Cultivar, inoculation timing } & \multirow[b]{2}{*}{ Average RH $(\%)^{\mathbf{a}}$} & \multicolumn{2}{|c|}{ Temperature $\left({ }^{\circ} \mathbf{C}\right)$} & \multirow[b]{2}{*}{ Harvest date } \\
\hline & & Minimum & Maximum & \\
\hline \multicolumn{5}{|l|}{ Red Delicious } \\
\hline 17 May 2012 & 99.4 & 4.9 & 22.1 & 2 October 2012 \\
\hline 20 June 2012 & 61.3 & 17.9 & 28.3 & 2 October 2012 \\
\hline 24 July 2012 & 94.9 & 16.8 & 34.9 & 2 October 2012 \\
\hline 20 September 2012 & 92.9 & 8.6 & 22.9 & 2 October 2012 \\
\hline 14 May 2013 & 82.6 & 9.4 & 30.8 & 25 September 2013 \\
\hline 13 June 2013 & 92.1 & 6.9 & 26.4 & 25 September 2013 \\
\hline 18 July 2013 & 88.7 & 17.5 & 36.2 & 25 September 2013 \\
\hline 20 August 2013 & 82.7 & 13.3 & 32.4 & 25 September 2013 \\
\hline 9 September 2013 & 91.8 & 14.8 & 28.0 & 25 September 2013 \\
\hline 19 May 2014 & 84.3 & 10.1 & 30.4 & 17 September 2014 \\
\hline 18 June 2014 & 84.8 & 13.3 & 28.0 & 17 September 2014 \\
\hline 24 July 2014 & 89.1 & 12.1 & 34.5 & 17 September 2014 \\
\hline 21 August 2014 & 96.6 & 15.6 & 27.2 & 17 September 2014 \\
\hline 9 September 2014 & 95.2 & 11.3 & 34.9 & 17 September 2014 \\
\hline \multicolumn{5}{|l|}{ Fuji } \\
\hline 17 May 2012 & 99.4 & 4.9 & 22.1 & 25 October 2012 \\
\hline 20 June 2012 & 61.3 & 17.9 & 28.3 & 25 October 2012 \\
\hline 24 July 2012 & 94.9 & 16.8 & 34.9 & 25 October 2012 \\
\hline 20 September 2012 & 92.9 & 8.6 & 22.9 & 25 October 2012 \\
\hline 9 October 2012 & 93.9 & 3.2 & 24.4 & 25 October 2012 \\
\hline 14 May 2013 & 82.6 & 9.4 & 30.8 & 22 October 2013 \\
\hline 13 June 2013 & 92.1 & 6.9 & 26.4 & 22 October 2013 \\
\hline 18 July 2013 & 88.7 & 17.5 & 36.2 & 22 October 2013 \\
\hline 22 August 2013 & 92.9 & 17.9 & 27.2 & 22 October 2013 \\
\hline 11 September 2013 & 93.2 & 18.7 & 34.5 & 22 October 2013 \\
\hline 3 October 2013 & 92.1 & 4.5 & 21.7 & 22 October 2013 \\
\hline 20 May 2014 & 90.2 & 11.7 & 34.1 & 15 October 2014 \\
\hline 19 June 2014 & 83.9 & 15.2 & 35.3 & 15 October 2014 \\
\hline 24 July 2014 & 79.9 & 12.1 & 29.1 & 15 October 2014 \\
\hline 21 August 2014 & 96.4 & 15.2 & 26.0 & 15 October 2014 \\
\hline 9 September 2014 & 98.4 & 20.2 & 29.9 & 15 October 2014 \\
\hline 2 October 2014 & 93.2 & 5.3 & 17.5 & 15 October 2014 \\
\hline
\end{tabular}

${ }^{a}$ Relative humidity $(\mathrm{RH})$ was averaged over the entire course of incubation, lasting approximately $15 \mathrm{~h}$ for each inoculation timing. 
complete block design, with a total of three replicates per treatment and 40 fruit per replicate. Depending on fruit set, one to three trees were used to attain a sufficient number of fruit necessary to represent a single replicate. Fruit were sprayed to run-off with inoculum of either $N$. kienholzii, $N$. perennans, or sterile distilled water as the control using a hand sprayer. Inoculated fruit were immediately covered with a moistened white plastic trash bag of varying sizes $(15,30$, and 49 liters) depending on the length of the tree branch that fruit were growing on. Bags were sealed using clothespins in order to maintain high humidity to facilitate the establishment of infection. A WatchDog data logger (Spectrum Technologies, Inc., Aurora, IL) was placed into one of the bags during each inoculation date to record temperature and relative humidity experienced during each incubation period (Table 1). Plastic bags were removed from the fruit approximately $15 \mathrm{~h}$ postinoculation, and fruit remained on the tree until harvest. Fruit were harvested at commercial maturity, and harvest was conducted in the morning on the dates indicated in Table 1. After harvest, fruit were transported to Washington State University Tree Fruit Research and Extension Center in Wenatchee, WA for visual inspection. Fruit were manually sorted to remove any apple fruit with obvious injuries or abnormalities. Fruit were then packed onto fiberboard fruit trays and placed inside cardboard boxes lined with polyethylene bags. Packed fruit were stored in regular atmosphere (RA) at $0^{\circ} \mathrm{C}$ for up to 10 months (about 4 months longer than commercial RA standards).

Disease evaluations. Due to the differential fruit maturation timing common to the two cultivars used in this study, Red Delicious apple fruit were harvested 1 month prior to Fuji fruit. Thus, visual disease evaluations were initiated after 4 months of cold storage for Red Delicious and after 3 months for Fuji. Any fruit exhibiting symptoms resembling bull's-eye rot or with unidentifiable lesions were removed from their boxes, and information pertaining to treatment was recorded. Tissue was excised from the margin of lesions and placed onto PDA for isolation of potential causal fungi. Cultures were incubated at $20^{\circ} \mathrm{C}$ for a period of 14 days. Resulting colony morphology and growth characteristics of fungi emerging from fruit tissue in media were used to verify pathogen presence (Dugan et al. 1993; Verkley 1999). Disease evaluations continued throughout the cold storage season on a monthly basis for 7 months (10 months total storage for Red Delicious and 9 months total storage for Fuji).

Statistical analysis. To determine the relationship between total bull's-eye rot appearing during postharvest cold storage and the timing of apple fruit inoculation with either $N$. perennans or N. kienholzii in the orchard, the incidence of diseased fruit from each replicate of each treatment was arcsine square root transformed and subjected to a linear regression analysis using SAS PROC REG (version 9.4; SAS Institute, Cary, NC), with date of fruit harvest indicated by time 0 and date of fruit inoculation prior to harvest designated with negative values. To assess whether differences in the relative capacity of these two fungi to incite disease exists, disease incidence for the three treatments was analyzed within a single month following a generalized linear model using SAS PROC GENMOD. The standard addition transformation was applied to all incidence values to account for an excess of zeros observed in the control treatment. Means separation was computed following the Tukey method (Tukey 1949; $P \leq 0.05$ ).

\section{Results}

In general, average relative humidity during the fruit inoculation incubation period ranged from 80 to $99 \%$, with the exception of inoculations conducted in June 2012 when average relative humidity was recorded at $61 \%$. Typically, the highest temperature during the postinoculation incubation period was recorded in July (approximately $35^{\circ} \mathrm{C}$ ), with the exception of Red Delicious fruit inoculations completed in 2014, when the highest recorded temperature during incubation was experienced in September $\left(34.9^{\circ} \mathrm{C}\right)$, and Fuji inoculations in 2014 , when the highest incubation temperature occurred in June $\left(35.5^{\circ} \mathrm{C}\right)$. Temperature trends were usually cooler in May, September, and October, and warmest in July (Table 1).

Symptomatic fruit were recovered during each disease rating, demonstrating that, when held in cold storage at $0^{\circ} \mathrm{C}$, bull's-eye rot symptoms can manifest as early as 3 months into the postharvest season and as late as 10 months. Bull's-eye rot lesions were commonly observed at fruit lenticels; however, occasionally lesions originating at the calyx and stem bowl region of fruit were also recorded. It should also be noted that bull's-eye rot was observed and the pathogen recovered from fruit treated with the water control representing multiple inoculation timings. Disease incidence for the control was limited, ranging from 0 to $2.5 \%$, with only one occurrence where fruit rot reached 5.0\% (Fuji apple fruit inoculated in June 2013). These infections may represent natural sources of inoculum present in the orchard. No attempts were made to identify which Neofabraea sp. induced these infections.

With the exception of Red Delicious apple fruit inoculated with N. kienholzii during May 2013, postharvest development of bull'seye rot was confirmed from both apple cultivars representing each inoculation timing tested in this study. This demonstrates that, regardless of apple fruit physiology, fruit infection by Neofabraea spp. can be initiated throughout the entire fruit growing season if favorable conditions for infection are met. In general, bull's-eye rot incidence increased gradually when fruit were inoculated early in the growing season, declined in July, and then continued to increase for the remainder of the fruit growing season. This could suggest inhibition of fungal growth when temperatures approach or exceed $30^{\circ} \mathrm{C}$. Total fruit infection by either pathogen was consistently greatest when inoculations took place at the end of the growing season compared with early or midseason infections. Excluding Red Delicious apple fruit inoculated with $N$. kienholzii in 2014, the relationship between total postharvest bull's-eye rot resulting from $N$. perennans or $N$. kienholzii inoculations increased significantly $(P \leq 0.04)$ in a linear manner as the timing of fruit inoculation approached harvest (Fig. 1).

Disease incidence for Red Delicious apple fruit inoculated with either Neofabraea spp. was significantly different from the control treatment at each inoculation timing tested during the 2012 fruit growing season (Fig. 2A). When inoculations were held in September 2012, $N$. perennans induced significantly greater disease than $N$. kienholzii $(P<0.0001)$. However, no significant difference in disease incidence between the two pathogens was detected at any other inoculation timing tested during that year. In 2013, significantly more disease was attributed to $N$. perennans compared with $N$. kienholzii or the control except for inoculations conducted in July, during which disease incidence was low and not significantly different between the three treatments (Fig. 2B). Additionally, no disease was observed from fruit inoculated with $N$. kienholzii during the May inoculation timing. For inoculations conducted during the 2014 fruit growing season (Fig. 2C), disease incidence was significantly greater for $N$. perennans compared with $N$. kienholzii during the months of July, August, and September 2014. In general, disease incidence on the fruit inoculated with N. kienholzii in 2014 was very low, and only significantly different from the control treatment during the September inoculation timing.

When inoculations were conducted on Fuji apple fruit during the 2012 fruit growing season (Fig. 3A), disease incidence for $N$. perennans and $N$. kienholzii was significantly greater than the control during each inoculation timing, except in July, when disease levels were low for both pathogens. Additionally, significantly more fruit were infected when $N$. perennans was used as the inoculum source compared with $N$. kienholzii for inoculations conducted in September, whereas the opposite was true for inoculations completed in October. No detectable difference in disease incidence could be discerned between the two pathogens at any other inoculation timing during that year. In 2013 (Fig. 3B), N. perennans incited significantly more disease than $N$. kienholzii when inoculations were conducted in May, June, and September, whereas inoculations held in July and October resulted in significantly more $N$. kienholzii infections. No significant difference in disease incidence between the two pathogens was detected for fruit inoculated in August. During the 2014 fruit growing season (Fig. 3C), N. perennans caused more disease than N. kienholzii at each inoculation period except June, when no significant difference in disease was detected between the two pathogens $(P=0.3271)$, and except in October, when $N$. kienholzii induced significantly more fruit infections. Due to low disease incidence by $N$. kienholzii, no significant difference between the control and $N$. kienholzii treatment could be 
detected during the May $(P=0.0674)$ and July $(P=0.2467)$ inoculations.

\section{Discussion}

Results from these studies demonstrate that both Red Delicious and Fuji apple cultivars are susceptible to fruit infection by the bull'seye rot-causing pathogens throughout the growing season but are most susceptible to infection during the final weeks prior to fruit harvest. These results are consistent with the disease cycles of other major pome fruit postharvest pathogens resident to the PNW such as $P$. washingtonensis (Sikdar et al. 2014) and Sphaeropsis pyriputrescens (Kim et al. 2014). In artificial inoculations, infection by $N$. perennans and $N$. kienholzii increased gradually over the course of the growing season, with the exception of a sharp decline occurring during the July inoculation time point (for trials conducted in 2012 and 2013). This was followed by a sharp increase in disease incidence for fruit inoculated during the final two to three inoculation timings. Although there were some fluctuations between the infection capabilities of the two bull's-eye rot pathogens, overall, $N$. perennans and $N$. kienholzii were capable of inducing disease at comparable levels. This indicates that, although only recently identified as a component of the pathogen complex inciting bull's-eye rot of apple (de Jong et al. 2001), N. kienholzii appears to be well adapted to the conditions encountered in the major pome-fruit growing regions of central Washington (Gariepy et al. 2005; Spotts et al. 2009). Additionally, although bull's-eye rot symptoms were not visible at harvest, typical bull's-eye lesions were observed as early as 3 months into the cold storage season and were initiated by as late as the 10th month of storage (data not shown).

Most fungal postharvest pathogens gain entry into their hosts either through wounds, direct penetration of intact tissue, or colonization of natural openings such as lenticels, stems, and pedicels (Prusky and Lichter 2007). Neofabraea spp. causing bull's-eye rot primarily enter their hosts via open lenticels appearing on the surface of fruit skin (Edney 1956). Although lenticel number is static throughout maturity, lenticels can enlarge due to lengthening of microcracks within the cuticle in response to fruit growth (Harker and Ferguson 1988). One explanation as to the propensity for bull's-eye rot pathogens to cause greater disease near the end of a growing season could be due to changes in the availability of these natural openings with response to fruit maturity. Over time, mineral content and other environmental factors may influence the breakdown of lenticels (Turketti et al. 2012). Changes to the structural integrity of these lenticels throughout development may facilitate their accessibility by pathogen propagules. The importance of structural resistance to infection by lenticel-colonizing fungi was demonstrated by Guan et al. (2015), who showed that apple ring rot caused by Botryosphaeria dothidea was more severe in cultivars exhibiting a higher number of natural openings and a thinner layer of cuticular wax on the fruit surface. As apple fruit approach maturity, spores of $N$. perennans and $N$. kienholzii are likely better able to exploit the vulnerabilities of a weakened cuticle and, thus, can invade lenticels of their host to a much higher success rate.

Successful invasion of a host is influenced by the metabolic processes occurring in both host and pathogen at the time of infection. Processes occurring during the early development of fruitlets may vary drastically from those occurring near the completion of fruit maturation. For example, levels of total phenolic compounds isolated from apple fruit flesh and skin were found to decrease significantly with fruit maturity, and these compounds were found to be inhibitory to B. ribis infection of immature fruit (Hwang 1983). Similarly, increased production of the antifungal diene, 1-acetoxy2-hydroxy-4-oxo-heneicosa-12,15-diene in unripe avocado is inhibitory to colonization by the postharvest pathogen Colletotrichum gloeosporioides (Prusky 1996; Prusky and Lichter 2007; Prusky et al. 1983; Wang et al. 2004). However, as fruit ripen, the diene becomes metabolized by avocado lipoxygenase (Karni et al. 1989; Prusky and Lichter 2007), leaving fruit vulnerable to cell-wall-degrading enzymes produced by $C$. gloeosporioides; namely, pectate lyase and polygalacturonase (Prusky and Lichter 2007; Wattad et al. 1994). Additionally, secretion of proteases by Nectria galligena was shown
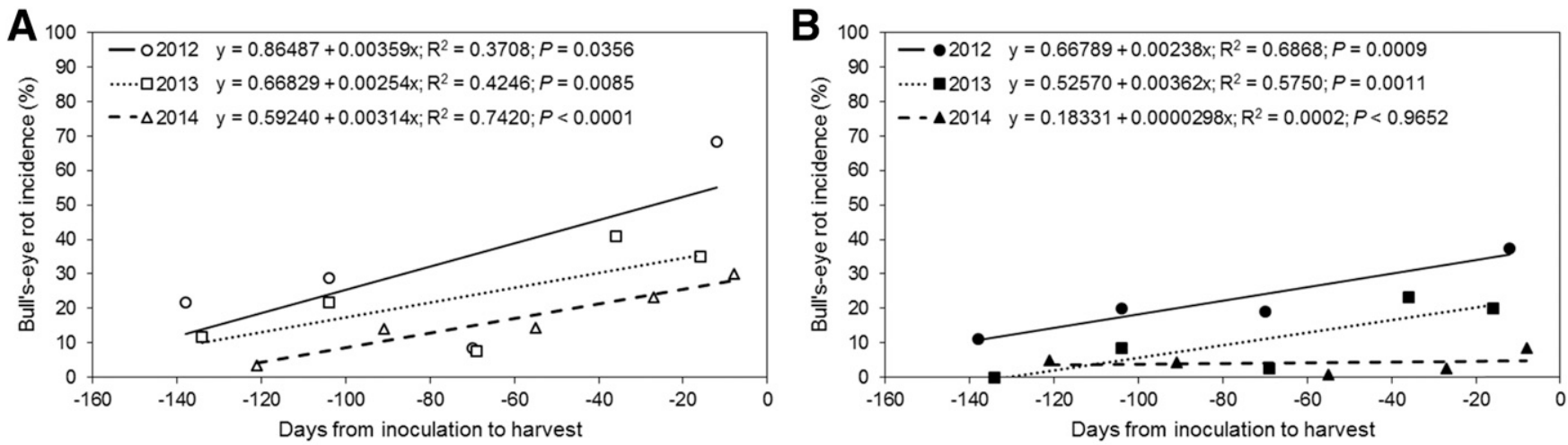

C

D
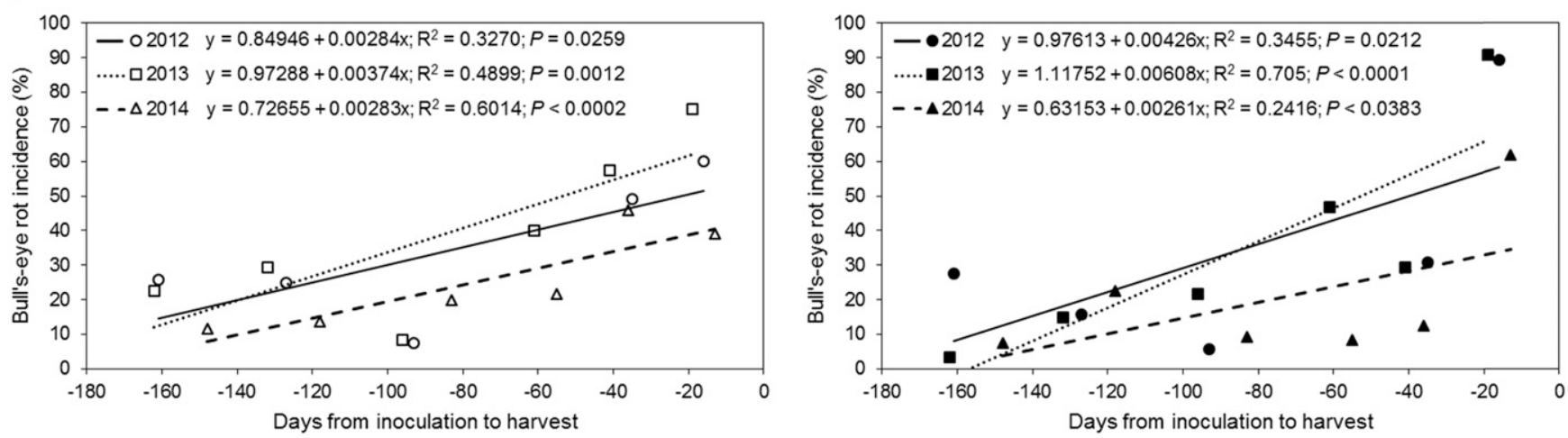

Fig. 1. Scatterplot showing the linear relationship between timing of $\mathbf{A}$ and $\mathbf{B}$, Red Delicious and $\mathbf{C}$ and $\mathbf{D}$, Fuji apple fruit inoculated with either Neofabraea perennans (A and $\mathrm{C}$ ) or N. kienholzii ( $\mathrm{B}$ and $\mathrm{D}$ ) in the orchard and total bull's-eye rot development obtained by the end of the cold storage season. Harvest date is indicated by day 0 and inoculation date is represented by negative integers. Values shown are the percentage of diseased apple fruit out of the total number of fruit inoculated for each treatment, averaged across three replicates. 
to behave as an elicitor for benzoic acid production in immature apple fruit, restricting colonization of host tissue by the pathogen. However, during ripening, $\mathrm{pH}$ and sugar content within fruit increase, creating an environment favoring fungal degradation of benzoic acid (Brown and Swinburne 1973). Protease secretion and variations to benzoic acid concentrations over the course of fruit ripening have been shown to play important roles in eliciting infections by quiescent pathogens such as Nectria galligena and Neofabraea spp. (Swinburne 1975). Still, the metabolic processes conferring resistance to pathogen invasion in apple fruit may be far more dynamic than initially perceived. In a study conducted by Janisiewicz et al. (2016), production of reactive oxygen species (ROS) declined sharply in accession lines of wild $M$. sieversii resistant to Penicillium expansum immediately after fruit were wounded. Counterintuitively, certain accession lines deemed highly susceptible to $P$. expansum infection produced high levels of ROS. These results indicate that the metabolic processes historically regarded as necessary for pathogen inhibition may not always behave in a predictable manner and may interact in a way that is far more complicated than initially interpreted. Studies examining the defense response of fruit to invasion by Neofabraea spp. are lacking.

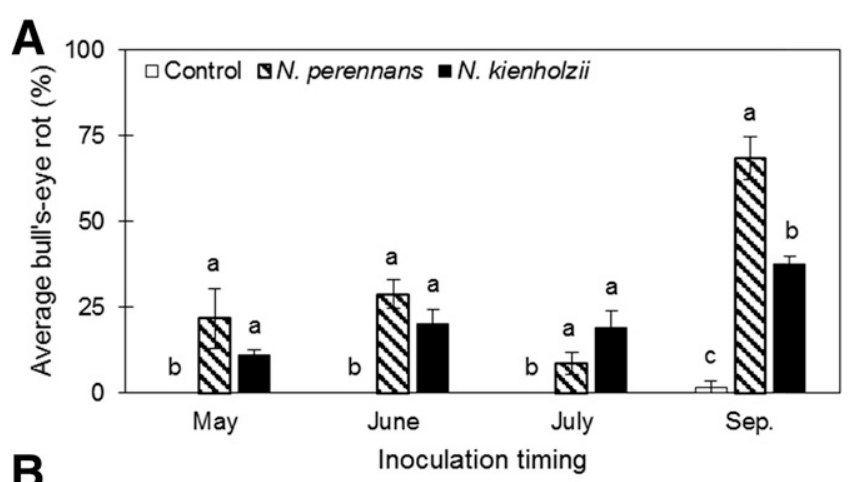

B
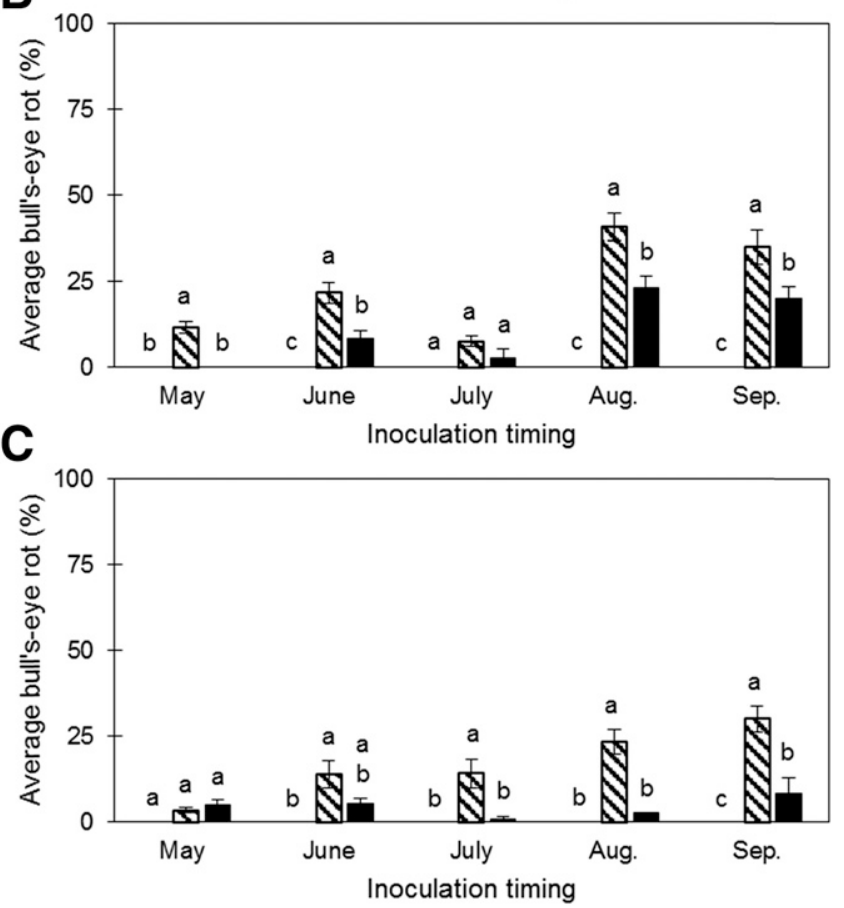

Fig. 2. Average total incidence of bull's-eye rot on Red Delicious apple. Apple fruit were inoculated in the orchard with a spore suspension of Neofabraea perennans or N. kienholzii at various inoculation timings during the A, 2012; B, 2013; and C, 2014 fruit growing seasons. Fruit were harvested at commercial maturity and kept under postharvest storage at $0^{\circ} \mathrm{C}$ for 10 months. Monthly disease ratings were conducted beginning on the fourth month of storage. Difference in total disease incidence for $N$. perennans and N. kienholzii at each inoculation timing was compared. Means represented by bars within the same inoculation timing and designated with the same letter are not significantly different $(P \leq 0.05)$.
Unlike $P$. expansum, which can produce blue mold symptoms relatively shortly after colonizing wounds on apple fruit, bull's-eye rotcausing fungi undergo a period of inactivation (otherwise known as quiescence) shortly after coming into contact with host tissue. During quiescence, fungal growth and disease development are arrested, resuming only after certain physiological or biochemical cues in the host have been satisfied (Coats and Johnson 1997). As was demonstrated in this study, the length of quiescence for bull's-eye rot-causing species can vary tremendously depending upon how early during the growing season fungal spores have made contact with their host. Quiescence in the Neofabraea-apple pathosystem appears to be disrupted shortly after harvest but the exact timing and cues causing this transition are unknown and should be the subject of future investigations. As climacteric fruit, apple fruit continue to undergo respiration and transpiration after harvest. While in cold storage, these processes continue, albeit at a slower rate, depending on storage conditions (Thompson 1998). As time progresses, fruit continue to senesce and ripen, causing an accumulation in ethylene production and depletion of stored nutrients and water reserves (Coats and Johnson 1997). Transition out of quiescence for Neofabraea spp. is likely affected by the availability of nutrients
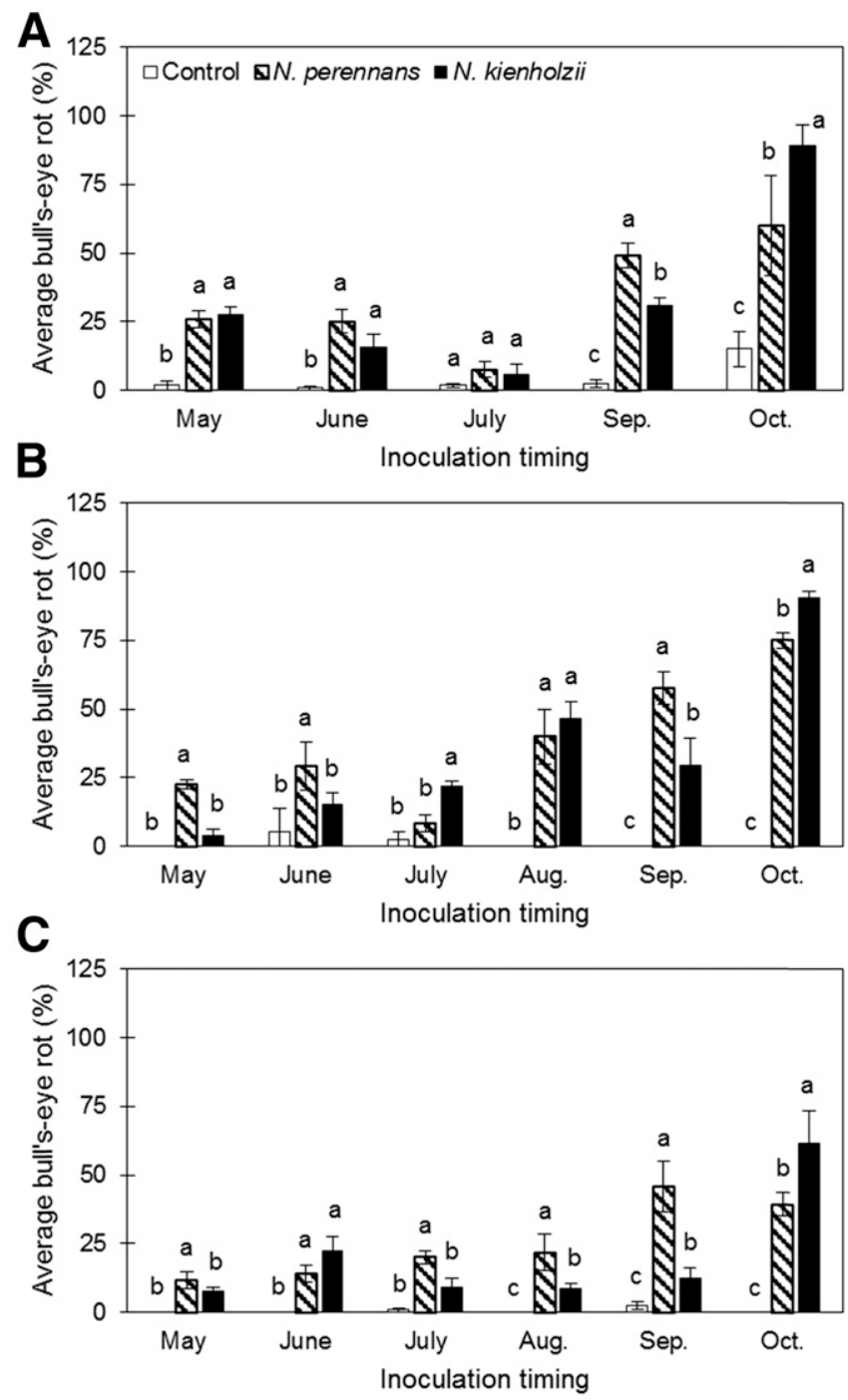

Fig. 3. Average total incidence of bull's-eye rot on Fuji apple. Apple fruit were inoculated in the orchard with a spore suspension of Neofabraea perennans or $N$. kienholzii at various inoculation timings during the A, 2012; B, 2013; and C, 2014 fruit growing seasons. Fruit were harvested at commercial maturity and kept under postharvest storage at $0^{\circ} \mathrm{C}$ for 9 months. Monthly disease ratings were conducted beginning on the third month of storage. Difference in total disease incidence for $N$. perennans and N. kienholzii at each inoculation timing was compared. Means represented by bars within the same inoculation timing and designated with the same letter are not significantly different $(P \leq 0.05)$. 
during storage but is also in response to volatile production during ripening.

Fruit infection by Neofabraea perennans and N. kienholzii was observed at every inoculation timing tested in this study, suggesting that, although temperature and other environmental factors may be important influences of infection, they are not necessarily determinants of infection. It seems likely that the fungi causing bull's-eye rot are capable of withstanding a wide range of temperatures (Henriquez et al. 2008). Similarly, minimal infection during the July inoculation timing may indicate an aversion to higher temperatures, because average daytime temperatures experienced in central Washington often exceed $30^{\circ} \mathrm{C}$ during this time. Molecular and physiological processes affecting pathogen and host interactions during the initial phases of host colonization may be more important predictors for successful infection. However, it is important to mention that, although temperature and other conditions may not affect the infection process directly, their effect on host and pathogen health can indirectly influence host susceptibility to infection. By enclosing fruit in moistened bags during the inoculation procedure, an optimum microclimate was created on the fruit surface. The 15 -h incubation period during which fruit were exposed to these conditions helped facilitate the establishment of infections. Because Neofabraea spp. are quiescent pathogens of pome fruit, $N$. perennans and $N$. kienholzii must be resilient to withstand a variety of environmental conditions before resuming the infection process after harvest. The intricacies of the environment and its influence over host-pathogen interactions should be explored further to better develop predictive models that can assess the risks associated with orchard practices on fruit infection and subsequent postharvest decay in storage.

Because Neofabraea spp. exhibit a higher success in initiating infection near the end of the apple fruit growing season, application of a systemic fungicide during the final weeks leading up to harvest or after harvest should help minimize the incidence of this disease (Coats and Johnson 1997). By targeting this period, a reduction in frequency of fungicide applications can be attained. Additionally, management practices prior to the commencement of the growing season should be directed toward scouting and removal of tree cankers in the orchard because these are the primary source of pathogen inoculum. Further recommendations to help minimize pathogen inoculum in the field include regular pruning and skirting to increase air circulation within the tree canopy and inhibit optimum conditions for infection. Decaying organic material such as twigs, leaves, and fruit should be removed from the orchard floor because these can also support the overwintering of pathogen propagules. Finally, because spore dispersal of bull's-eye rot pathogens is largely dependent on transmission via water splash, use of overhead sprinkler systems should be avoided (Henriquez et al. 2008).

\section{Acknowledgments}

We thank R. Boal, R. Caiazzo, M. Walter, and P. Sikdar for help during fruit inoculations and Achievement Rewards for College Scientists for providing financial assistance.

\section{Literature Cited}

Bompelx, G. 1978. The comparative development of Pezicula vagabunda and Pezicula malicorticis on apples in vitro and controlled atmosphere. Phytopathol. Z. 91:97-109.

Brown, A. E., and Swinburne, T. R. 1973. Factors affecting the accumulation of benzoic acid in Bramley's Seedling apples infected with Nectria galligena. Physiol. Plant Pathol. 3:91-99.

Bush, M. J., Dunley, J., Beers, E. H., Brunner, J. F., Grove, G. G., Xiao, C. L., Elfving, D. C., Peryea, F., Schrader, L., Parker, R., Smith, T. J., Daniels, C., Maxwell, T., Foss, S. L., Johnson, E., and Tangren, J. 2008. 2008 Crop protection guide for tree fruits in Washington. Wash. State Univ. Ext. Bull. EB 0419

Childs, L. 1929. The relation of wooly apple aphid to perennial canker infection with other notes on the disease. Ore. Agric. Exp. Stn. Bull. 243:31.

Coates, L., and Johnson, G. 1997. Postharvest diseases of fruit and stored vegetables. Pages 533-547 in: Plant Pathogens and Disease. J. F. Brown and H. J. Ogle, eds. University of New England Printery, Armidale, NSW, Australia.

Creemers, P. 2014. Anthracnose canker and perennial canker. Pages 51-53 in: Compendium of Apple and Pear Diseases and Pests, 2nd ed. T. B. Sutton, H. S. Aldwinckle, A. M. Agnello, and J. F. Walgenbach, eds. American Phytopathological Society, St. Paul, MN. de Jong, S. N., Levesque, C. A., Verkley, G. J. M., Abelin, E. C. A., Rahe, J. E., and Braun, P. G. 2001. Phylogenetic relationships among Neofabraea species causing tree cankers and bull's eye rot of apples based on DNA sequencing of ITS nuclear rDNA, mitochondrial rDNA, and the $\beta$-tubulin gene. Mycol. Res. 105:658-669.

Dugan, F., Grove, G. G., and Rogers, J. D. 1993. Comparative studies of Cryptosporiopsis curvispora and C. perennans. I. Morphology and pathogenic behavior. Mycologia 85:551-564.

Edney, K. L. 1956. The rotting of apples by Gloeosporium perennans Zeller and Childs. Ann. Appl. Biol. 44:113-128.

Gariépy, T. D., Lévesque, C. A., de Jong, S. N., and Rahe, J. E. 2003. Species specific identification of the Neofabraea pathogen complex associated with pome fruits using PCR and multiplex DNA amplification. Mycol. Res. 107:528-536.

Gariepy, T. D., Rahe, J. E., Lévesque, C. A., Spotts, R. A., Sugar, D. L., and Henriquez, J. L. 2005. Neofabraea species associated with bull's-eye rot and cankers of apple and pear in the Pacific Northwest. Can. J. Plant Pathol. 27: 118-124.

Grove, G., Dugan, F. M., and Boal, R. 1992. Perennial canker of apple: Seasonal host susceptibility, spore production and perennation of Cryptosporiopsis perennans in infected fruit in Eastern Washington. Plant Dis. 76:1109-1114.

Guan, Y., Chang, R., Liu, G., Wang, Y., Wu, T., Han, Z., and Zhang, X. 2015. Role of lenticels and microcracks on susceptibility of apple fruit to Botryosphaeria dothidea. Eur. J. Plant Pathol. 143:317-330.

Harker, F. R., and Ferguson, I. B. 1988. Transport of calcium across cuticles isolated from apple fruit. Sci. Hortic. (Amsterdam) 36:205-217.

Henriquez, J. L., Sugar, D., and Spotts, R. A. 2008. Effects of environmental factors and cultural practices on bull's eye rot of pear. Plant Dis. 92:421-424.

Hwang, B. K. 1983. Contents of sugars, fruit acids, amino acids and phenolic compounds of apple fruits in relation to their susceptibility to Botryosphaeria ribis. Phytopathol. Z. 108:1-11.

Janisiewicz, W. J., Nichols, B., Bauchan, G., Chao, T. C., and Jurick, W. M., II. 2016. Wound responses of wild apples suggest multiple resistance mechanism against blue mold decay. Postharvest Biol. Technol. 117:132-140.

Karni, L., Prusky, D., Kobiler, I., Bar-Shira, E., and Kobiler, D. 1989. Involvement of epicatechin in the regulation of lipoxygenase activity during activation of quiescent Colletotrichum gloeosporioides infections of ripening avocado fruits. Physiol. Mol. Plant Pathol. 35:367-374.

Kienholz, J. R. 1938. Comparative study of the apple-tree anthracnose and perennial-canker fungi. Ph.D. dissertation, Oregon State College, Corvallis.

Kienholz, J. R. 1939. Comparative study of the apple anthracnose and perennial canker fungi. J. Agric. Res. 59:635-665.

Kim, Y. K., Curry, E. A., and Xiao, C. L. 2014. Infection of apple fruit by Sphaeropsis pyriputrescens in the orchard in relation to Sphaeropsis rot in storage. Eur. J. Plant Pathol. 140:133-143.

Prusky, D. 1996. Pathogen quiescence in postharvest diseases. Annu. Rev. Phytopathol. 34:413-434.

Prusky, D., Keen, N. T., and Eaks, I. 1983. Further evidence for the involvement of preformed antifungal compounds in the latency of Colletotrichum gloeosporioides on unripe avocado fruits. Physiol. Mol. Plant Pathol. 22: 189-198, IN5.

Prusky, D., and Lichter, A. 2007. Activation of quiescent infections by postharvest pathogens during transition from the biotrophic to the necrotrophic stage. FEMS Microbiol. Lett. 268:1-8.

Sharples, R. O. 1959. Further orchard sources of infection by Gloeosporium spp Plant Pathol. 8:71-72.

Sikdar, P., Mazzola, M., and Xiao, C. L. 2014. Infection courts and timing of infection of apple fruit by Phacidiopycnis washingtonensis in the orchard in relation to speck rot during storage. Plant Dis. 98:1467-1475.

Spotts, R. A. 2014. Bull's-eye rot. Pages 78-79 in: Compendium of Apple and Pear Diseases and Pests, 2nd ed. T. B. Sutton, H. S. Aldwinckle, A. M. Agnello, and J. F. Walgenbach, eds. American Phytopathological Society, St. Paul, MN.

Spotts, R. A., Seifert, K. A., Wallis, K. M., Sugar, D., Xiao, C. L., Serdani, M., and Henriquez, J. L. 2009. Description of Cryptosporiopsis kienholzii and species profiles of Neofabraea in major pome fruit growing districts in the Pacific Northwest USA. Mycol. Res. 113:1301-1311.

Swinburne, T. R. 1975. Microbial proteases as elicitors of benzoic acid accumulation in apples. Phytopathol. Z. 82:152-162.

Tan, A. M., and Burchill, R. T. 1972. The infection and perennation of the bitter rot fungus, Gloeosporium album, on apple leaves. Ann. Appl. Biol. 70:199-206.

Thompson, A. K. 1998. Controlled Atmosphere Storage of Fruits and Vegetables. CAB International, Wallingford, UK.

Tukey, J. W. 1949. Comparing individual means in the analysis of variance. Biometrics 5:99-114.

Turketti, S. S., Curry, E., and Lötze, E. 2012. Role of lenticel morphology, frequency and density on incidence of lenticel breakdown in 'Gala' apples. Sci. Hortic. (Amsterdam) 138:90-95.

Verkley, G. J. M. 1999. A Monograph of the Genus Pezicula and Its Anamorphs. Studies in Mycology, 44. Centraalbureau voor Schimmelculture, Baarn, The Netherlands.

Wang, X., Lichter, A., Kobiler, I., Leikin-Frenkel, A., and Prusky, D. 2004. Expression of $\Delta^{12}$ fatty acid desaturate during the induced accumulation of the antifungal diene involved in resistance to Colletotrichum gloeosporioides in avocado fruits. Mol. Plant Pathol. 5:575-585. 
Warner, G. 2014. Washington apple producers hope to resume exports to China. Online publication. Good Fruit Grower. http://www.goodfruit.com/washingtonapple-producers-hope-to-resume-exports-to-china/

Wattad, C., Dinoor, A., and Prusky, D. 1994. Purification of pectate lyase produced by Colletotrichum gloeosporiodes and its inhibition by epicatechin: A possible factor involved in resistance of unripe avocado fruits to anthracnose. Mol. Plant-Microbe Interact. 7:293-297.

Wilkinson, E. H. 1944. Bitter rot of apples caused by Gloeosporium album Osterw., with special reference to the variety Allington Pippin. Pages 81-89 in: Annu. Rep. Long Ashton Agric. Hortic. Res. Stn.
Xiao, C. L., and Kim, Y. K. 2008. Postharvest fruit rots in apples caused by Botrytis cinerea, Phacidiopycnis washingtonensis and Sphaeropsis pyriputrescens. Online publication. Plant Health Prog. doi:10.1094/PHP-2008-0919-01DG

Xiao, C. L., Kim, Y. K., and Boal, R. J. 2011. Control of Sphaeropsis rot in stored fruit caused by Sphaeropsis pyriputrescens with postharvest fungicides. Plant Dis. 95:1075-1079.

Yigzaw, A., and Bond, S. 2014. China lifts suspension on Washington apples USDA News Release No. 0245.14. Online publication. https://www.fas.usda. gov/newsroom/china-lifts-suspension-washington-state-apples 